\title{
Topography and Tropical Cyclone Structure Influence on Eyewall Evolution in Typhoon Sinlaku (2008)
}

\author{
Cheng-Hsiang Chih ${ }^{1}$, Kun-Hsuan Chou $^{1, *}$, and Sen Chiao ${ }^{2}$ \\ ${ }^{1}$ Department of Atmospheric Sciences, Chinese Culture University, Taipei, Taiwan, R.O.C. \\ ${ }^{2}$ Department of Meteorology and Climate Science, San Jose State University, San Jose, CA, U.S.A. \\ Received 20 May 2014, revised 8 May 2015, accepted 8 May 2015
}

\begin{abstract}
Typhoon Sinlaku (2008) was a tropical system that affected many countries in East Asia. Besides the loss of life and economic damage, many scientific questions are associated with this system that need to be addressed. A series of numerical simulations were conducted in this study using V3.2 of the advanced research version of the Weather Research and Forecasting (WRF-ARW) model to examine the impacts of different terrain conditions and vortex structures on the eyewall evolution when Sinlaku was crossing Taiwan. The sensitivity experiments using different vortex structures show that a storm of the same intensity with a larger eyewall radius tends to induce stronger wind and rainfall at the outer part of the storm during the terrain-crossing period. This result suggests that the vortex contained with larger angular momentum is more favorable to reform a new eyewall from the contraction of the outer rainband after being affected by terrain. Based on these sensitivity experiments it is suggested that the topography and the tropical cyclone (TC) structure play important roles in regulating the outer tangential wind speed and modulating the unique eyewall evolutions for TCs passing Taiwan. A stronger vortex structure could lead to more precipitation at the outer part of the storm during the terrain influenced period, implying that the forecasters should pay attention to the storm intensity and also the storm structure which is an important dynamic feature that modulates the eyewall evolution and rainfall distribution of a landfalling storm.
\end{abstract}

Key words: Eyewall evolution, Eyewall breakdown, Eyewall reorganization

Citation: Chih, C. H., K. H. Chou, and S. Chiao, 2015: Topography and tropical cyclone structure influence on eyewall evolution in Typhoon Sinlaku (2008). Terr. Atmos. Ocean. Sci., 26, 571-586, doi: 10.3319/TAO.2015.05.08.01(A)

\section{INTRODUCTION}

Landfalling typhoons pose a serious and ongoing threat to Taiwan as well as other adjacent countries. As a typhoon makes landfall and moves inland, changes in structure and intensity can make a huge difference in the impacts along the coast and farther inland. Typhoon intensity is a scientific issue instrumental for assessing potential storm damage. However, the storm structure is usually a better parameter to determine the wind field and precipitation influence area for a storm. In the past two decades many observational analysis studies have focused on evaluating the tracks of land falling typhoons in Taiwan (e.g., Yeh and Elsberry 1993a, b; Wu and Kuo 1999; Wu 2001; Wu et al. 2002). Numerical simulations with various data assimilation techniques (e.g., Huang et al. 2002, 2005; Xiao et al. 2005, 2007; Wu et al. 2007,

\footnotetext{
* Corresponding author

E-mail: zkx@faculty.pccu.edu.tw
}

2012; Yang et al. 2009a, b) have shown that assimilating unconventional datasets can further improve track forecasting.

The interaction between the vortex structure and topography cannot be ignored in improving the track forecasting. Some recent studies also focused on examining southward-deflected tracks when storms were influenced by topography. For instance, Lin et al. (2005) conducted idealized simulations with higher resolution, but without moist physics and the surface friction effect. They introduced six non-dimensional parameters for the tropical cyclone (TC) track as inferred from previous studies. Jian and Wu (2008) also proposed a terrain-induced channel effect to explain the sharp southward turn of a westward moving storm. Experiments applying different structure parameter values illustrate that increasing the strength, size and translation speed of the initial storm results in a smaller interaction with Taiwan's terrain and a smaller average steering flow caused 
by the asymmetric circulation, which leads to a proportionally smaller southward track deflection without making a loop. Huang et al. (2011) used a full-physics model to investigate the eminent typhoon track deflection prior to its landfall over mountainous island topography. Their results showed that the Taiwan terrain height plays the most important role in Typhoon Krosa's looping motion at its landfall. The surface properties, details in the topographic shape of Taiwan, and the cloud microphysics are shown to be secondary to the track deflection. Both real-case and idealized simulations show strong channel winds enhanced between the storm and the terrain when deflection occurs. Hsu et al. (2013) examined the topographically phase-locked convection effect on the motion of typhoons across the island of Taiwan. Their numerical studies showed that the topographically phase-locked convection acts to slow down (speed up) northern (southern) landfalling typhoons. These results suggested that a positive feedback mechanism exists for the slow storms. The convective heating pattern forced by topography acts to reduce the storm motion, which leads to even more prolonged precipitation and heating, as well as further speed reductions.

A recent study by Rogers (2010) addressed the importance of convective bursts in rapid intensification by examining the structure and evolution of convective-scale processes prior to and during rapid intensification. It was found that the onset of rapid intensification is linked to an increase in the areal extent of convective precipitation in the inner core, while the inner core stratiform precipitating area remains unchanged. This result supports the assertion that both buoyantly driven updrafts and slantwise near-neutral ascent are important features in eyewall structure, evolution and intensification, including rapid intensification. Chan (2012) summarized that the roughness, moisture and topography effects would produce asymmetric convection as TCs make landfall. Subsequently, the potential vorticity tendency distribution can be changed in association with tracks. Although it is well understood that the topographic effect may affect the TC track, structure and intensity, few studies have focused on asymmetric landfalling TCs over mountainous terrain. The extreme amounts of precipitation associated with landfalling TCs have increased significantly in the past decade (e.g., Hurricane Sandy 2012, Typhoon Morakot 2009, and Typhoon Haiyan 2013). Yang et al. (2013) examined the structure and intensity change of concentric eyewalls of typhoons in the western North Pacific basin using an objective method to identify concentric eyewalls from passive microwave satellite imagery. It was found that the typhoon intensity in the eyewall replacement cycle and concentric eyewall maintained cases weakens after concentric eyewall formation and the convective activity is maintained or increases. The concentric eyewall maintained cases have a relatively high intensity with the moat size and outer eyewall width approximately $50 \%$ larger than the other two categories. Both the internal dynamics and environmental conditions are important in the concentric eyewall maintained cases. The no replacement cycle cases are however, heavily influenced by the environment. The eyewall replacement cycle cases may be dominated by the internal dynamics because of more uniform environmental conditions.

In fact, the interactions between the TC structure and topography are extremely complicated. The above mentioned studies did not emphasize the TC size and strength factors which might affect the TC internal dynamics and external forcing. In other words, questions related to the TC structure evolution and rainband structures affected by topography are still not well understood. Normally, TC intensity is defined as maximum wind speed and minimum central surface pressure. TC strength could be defined as the spatially averaged wind speed over an annulus from the radius of maximum wind $\left(\mathrm{R}_{\max }\right)$ to some radii of storm and size is the averaged radius of gale force winds or of the outer closed isobar at the surface. Merrill (1984) suggested that the most direct and simple way to define a typhoon size is based on the radius of the outer close isobar (ROCI) and wind field, but it is a challenge to separate the environmental pattern and storm structure. Liu and Chan (2002) provided a definition for TC size using the mean radius of the relative vorticity of values greater than $1 \times 10^{-5} \mathrm{~s}^{-1}$. Xu and Wang $(2010 \mathrm{a}, \mathrm{b})$ measured the inner-core size using the radius of damaging wind (i.e., $25.7 \mathrm{~m} \mathrm{~s}^{-1}$ ). Nevertheless, a typhoon's size would not be the same based on ROCI and relative vorticity. The radius of damaging wind approach also lacks any dynamic constraint. Chen et al. (2011) suggested a structure parameter associated with TC size and strength. Notice that any two different vortex structures may have a similar structure parameter to represent the compactness or vice versa. They also pointed out that the low-level forcing (e.g., environmental inflow) mainly affects the size and strength of TCs. For the internal dynamics, the large $\mathrm{R}_{\max }$ favors the development of incompact TCs. Chan and Chan (2012) further defined the TC size by the azimuthally averaged radius of $17 \mathrm{~m} \mathrm{~s}^{-1}$ of ocean-surface winds (R17) and the azimuthally averaged tangential wind within $1^{\circ}-2.5^{\circ}$-latitude radius from the TC center (outer-core wind strength) from the QuikSCAT data. They found that the correlation between size and strength is strong, and that the correlation between intensity and either size or strength is weak. Rotunno and Emanuel (1987) and Cocks and Gray (2002) also indicated that the TC development tendency of a small initial vortex would be less than that of a large initial vortex in every developmental stage. The momentum budget calculation using the axisymmetric average tangential wind equation suggested that the inward transfer of angular momentum would generate positive feedback between TC size and intensity (Xu and Wang 2010a, b). However, the momentum budget calculation did not include the impacts from topography. Finally, Knaff et al. (2014) used infrared (IR) imagery to estimate TC size from 1978 - 2011. In order to 
solve the size definition problems these previous studies attempted to utilize many data and methods. Indeed, it would take a long time to construct an objective definition technique for TC size for climatology.

One of the challenging forecasting tasks for landfalling typhoons is the topographic effects on the eye and eyewall evolutions. Wu et al. (2003) proposed that the eyewall evolution of Typhoon Zeb (1998) before, during, and after its landfall at Luzon was documented from both the satellite observations and numerical simulation. It was found that the terrain played a critical role in such eyewall evolution wherein the first eyewall contraction just before landfall, its breakdown after landfall and then the reorganization of a larger outer eyewall after the storm returned to the ocean. Further detailed numerical examination of this unique eyewall evolution was documented in Wu et al. (2009). It was shown that the presence of Luzon played a critical role in the observed eyewall evolution. The eyewall replacement occurring in Typhoon Zeb was triggered by the mesoscale terrain that has a horizontal scale similar to the size of the typhoon. Furthermore, based on several sensitivity experiments, it was shown that both diabatic heating and surface friction are key factors for the maintenance and the reorganization of the outer eyewall when Zeb reentered the ocean. The statistical characteristics of the eyewall evolution induced by the landfall process and terrain interaction over Luzon Island of the Philippines and Taiwan was reported in Chou et al. (2011). Their statistical analyses pointed out that the island topography effect on landfalling TCs in the Philippines and Taiwan accounted for 87 and $89 \%$ of TC cases with eyewall expansion, respectively. Nevertheless, nearly $57 \%$ of TCs presented eyewall contraction when the TCs reentered the ocean.

Although this terrain induced eyewall evolution has been better documented from previous studies ( $\mathrm{Wu}$ et al. 2003, 2009; Chou et al. 2011), some issues remain unsolved and are yet to be addressed. Such as: (1) What is the connection between the eyewall structure evolution and island topography? (2) What is the impact of different vortex structures on the eyewall evolution when Sinlaku crossed Taiwan? It should be noted that although the numerical simulations of different vortex structures were conducted in the previous works of Jian and Wu (2008) and Hsu et al. (2013), their study focused only on the track and intensity evolution when the TC was influenced by mountainous island topography. Thus, this study is the first article to assess the vortex structure parameters that could affect the eyewall evolution of a landfalling TC storm. In section 2 outlines the overview of typhoon Sinlaku. Section 3 depicts the numerical model and sensitivity experiments. Results and discussion are given in section 4, and conclusions are given in section 5.

\section{OVERVIEW OF TYPHOON SINLAKU}

A tropical disturbance formed on 7 September 2008 to the northeast of Manila in the Philippines. Subsequently, the Joint Typhoon Warning Center (JTWC) issued a Tropical Cyclone Formation Alert on the developing tropical depression (TD) on September 8 (i.e., TD 15W). This system strengthened into a tropical storm and was named Sinlaku by the Japanese Meteorological Agency (JMA). The JTWC reported that Sinlaku had intensified into a category-2 typhoon on September 9. The system continued to intensify and reached its maximum 1-minute sustained winds of 125 knots which made it a category-4 typhoon. On September 13 Typhoon Sinlaku made landfall on Taiwan as a category-2 typhoon.

The system moved towards the northwest through Taiwan and then turned towards the northeast and moved back into the East China Sea and started moving slowly towards Japan. As a natural disaster in Taiwan, Typhoon Sinlaku (2008) caused more than 20 confirmed fatalities, induced bridges to collapse and wash away after heavy rain. This storm caused at least NTD\$22.2 million loss in agriculture. About 120000 residences experienced power outage during the storm and 1000 people were evacuated from flooding zones. Typhoon Sinlaku (2008) was an important typhoon case in T-PARC (the Observing System Research and Predictability Experiment Pacific Asian Regional Campaign) project with many ground-based observations, aircraft insitu measurements, dropwindsonde and airborne radar observations ( $\mathrm{Wu}$ et al. 2012). Note that although many unique data were taken from the T-PARC international field campaign, the research focus of this study is applying the numerical model to investigate the impacts of different terrain conditions and vortex structures on the eyewall evolution when Sinlaku crossed Taiwan. The detailed data validation and data assimilation issues are therefore not elaborated in this study.

\section{NUMERICAL MODEL AND EXPERIMENTAL DESIGN}

\subsection{Numerical Model}

The advanced research version of the Weather Research and Forecasting (WRF-ARW) model, version 3.2, is used in this study. A control simulation using a three-nested configuration with $30 \mathrm{~km}(160 \times 150), 10 \mathrm{~km}(301 \times 262)$, and $3.3 \mathrm{~km}(508 \times 508)$ grid spacing (Fig. 1a) was executed, using 27 vertical terrain following levels. The USGS 30-arcsecond database was used to generate the model topography and land use, applying 4-point averaging and a single-pass smoothing. Figure $1 \mathrm{~b}$ shows the Taiwan terrain height on domain 3. The initial conditions and time-dependent lateral boundary tendencies for the outer nest were provided by the Final (FNL) Operational Global Analysis data (i.e., $1.0 \times 1.0$ degree) of the National Center for Environmental Prediction. No four-dimensional data assimilation was applied, so a 120-h simulation was conducted starting at 0000 UTC 11 September 2008 to allow for $12 \mathrm{~h}$ of mesoscale 
"spin-up" from the FNL initial conditions. The spin-up period allowed mesoscale features to develop in the simulation (especially for those due to topography) and damped initial noises introduced through the FNL data interpolation onto the higher spatial resolution WRF grids.

The microphysics parameterization scheme used in this study is the Goddard scheme of Tao et al. (1989) that includes ice, snow and graupel processes suitable for high-resolution simulations. The cumulus parameterization scheme from Kain and Fritsch (1993) is used in the two coarse resolution domains. The Yonsei University scheme (Noh et al. 2003) is a non-local-K scheme with an explicit entrainment layer and a parabolic $\mathrm{K}$ profile in unstable mixed layer, which is used for the planetary boundary layer (PBL). The Dudhia shortwave radiation scheme (Dudhia 1989) and the Rapid Radiative Transfer Model (RRTM) longwave radiation scheme (Mlawer et al. 1997) are used in radiative processes (Skamarock et al. 2008). The domain setup and applied physical parameterizations in the experi- ments are briefly listed in Table 1 .

\subsection{Experimental Design}

In order to produce a reasonable typhoon structure and have a well-suited intensity and size, the bogus scheme based on the method described in Wu et al. (2002) is applied to the sensitivity experiments. The bogus scheme, which includes a Rankine vortex with the vortex information analyzed from the JTWC Best Track data, is implanted $6 \mathrm{~h}$ prior to the model's initial time (e.g., Low-Nam and Davis 2001; Chou and Wu 2008). The vortex wind profile is defined using the following equations:

$\mathrm{V}(\mathrm{r}, \mathrm{z})=\mathrm{F}(\mathrm{r}) \mathrm{w}(\mathrm{z})$

$\mathrm{F}(\mathrm{r})=\mathrm{V}_{\max } \frac{\mathrm{r}}{\mathrm{R}_{\max }} \quad\left(\mathrm{r} \leq \mathrm{R}_{\max }\right)$
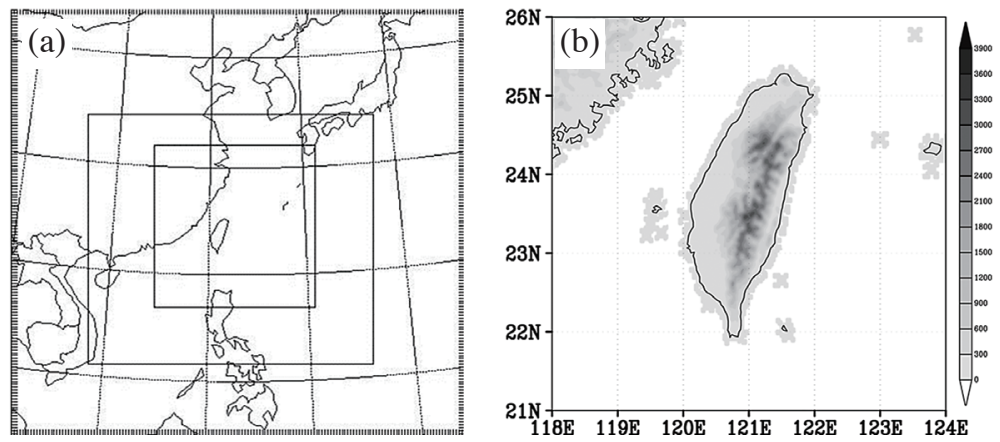

Fig. 1. (a) The three nested domains in all experiments; (b) the model's terrain height of Taiwan in domain 3, the contour interval is $300 \mathrm{~m}$.

Table 1. Information for the model configuration used in all the experiments.

\begin{tabular}{|c|c|c|c|}
\hline Model & \multicolumn{3}{|l|}{ WRF V3.2.0 } \\
\hline Central point & \multicolumn{3}{|l|}{$123^{\circ} \mathrm{E}, 25^{\circ} \mathrm{N}$} \\
\hline Projection & \multicolumn{3}{|c|}{ Lambert projection, and standard parallels were $15^{\circ}, 25^{\circ} \mathrm{N}$} \\
\hline Feedback & \multicolumn{3}{|l|}{ 2-way interaction } \\
\hline Vertical layer & \multicolumn{3}{|c|}{27 levels, $\sigma$ coordinates } \\
\hline & Domain 1 & Domain 2 & Domain 3 \\
\hline Horizontal Resolution & $30 \mathrm{~km}$ & $10 \mathrm{~km}$ & $3.33 \mathrm{~km}$ \\
\hline Grid number & $160 \times 150$ & $301 \times 262$ & $508 \times 508$ \\
\hline Time step & $180 \mathrm{sec}$ & $60 \mathrm{sec}$ & $20 \mathrm{sec}$ \\
\hline Shortwave radiation & Dudhia & Dudhia & Dudhia \\
\hline Longwave radiation & RRTM & RRTM & RRTM \\
\hline Microphysics & Goddard GCE & Goddard GCE & Goddard GCE \\
\hline Cumulus physics & Kain-Fritsch & Kain-Fritsch & None \\
\hline Boundary layer & YSU & YSU & YSU \\
\hline
\end{tabular}


$\mathrm{F}(\mathrm{r})=\mathrm{V}_{\max }\left(\frac{\mathrm{R}_{\max }}{\mathrm{r}}\right)^{\alpha} \quad\left(\mathrm{r}>\mathrm{R}_{\max }\right)$

Where $V_{\max }$ is the maximum tangential wind, $R_{\max }$ is the radius of maximum tangential wind, $\alpha$ is the decay coefficient of tangential wind, $w(z)$ is the weighting function used to calculate the maximum tangential wind at given height. A 6-h model integration is then performed to produce a spun-up, model-consistent, and asymmetric vortex structure. The model's three dimensional control variables in the storm core region were finally replaced using the above spun-up vortex as the new initial condition. Note that the circular region with a radius of $400 \mathrm{~km}$ is selected for vortex replacement in this study. Specifically, inside the inner $200-\mathrm{km}$ radius, the model data are completely replaced by the spun-up vortex, while a linear transition zone between the $200-$ and $400-\mathrm{km}$ radii is used to smoothly blend the spun-up vortex with the original global analysis. In the following experiments the linear transition zone is adjusted using the bogus size of radius parameter.

Two sets of experiments were conducted. The first set of experiments, including five experiments, is designed for terrain sensitivity to investigate the role of topography on the eyewall contraction and breakdown phenomena before and after Sinlaku crossed Taiwan. The control experiment (CTL) retains all of the mode-resolved terrain in the model domain and without bogused vortex implanted in the initial condition. In the second experiment (BMR) all conditions are the same with CTL, but the bogused vortex is implanted in the core region within the $400-\mathrm{km}$ radius from the storm center. The $\mathrm{V}_{\max }, \mathrm{R}_{\max }$, and $\alpha$ parameters for constructing the vortex structure are $65 \mathrm{~m} \mathrm{~s}^{-1}, 40 \mathrm{~km}$, and 0.2 , respectively. In the third experiment (T130), the Taiwan terrain was increased to $130 \%$ of the value resolved in the model. In the fourth experiment (FLAT), the Taiwan mountains (with a maximum height of $3257 \mathrm{~m}$ in the model) were flattened to 1-m height topography. In the fifth experiment (SEA), the Taiwan land was totally replaced with ocean. The terrain sensitivity experiment details are shown in Table 2.

The second set of experiments, which consists of three experiments, is designed to investigate the vortex structure (different radius of maximum wind, $\mathrm{R}_{\max }$ ) sensitivity in the interaction between Sinlaku and the Taiwan terrain. The initial vortex structure parameters for constructing these experiments are listed in Table 3. The three experiments are $\mathrm{R}_{\max }$ sensitivity experiments, which contain similar intensity $\left(V_{\max }\right.$ is $\sim 43 \mathrm{~m} \mathrm{~s}^{-1}$ ), while the $\mathrm{R}_{\max }$ is different. The values for $\mathrm{R}_{\max }$ are $0.37,0.45$, and 0.55 degree-latitude for BSR, BMR, and BLR, respectively (as shown in Fig. 2).

Note that the spin-up issue is very obvious when the initial condition is implanted with an axisymmetric vortex. This leads to the fact that the vortex structure could not be maintained by the given profile formulated by Rankine vortex equations. Thus, the vortex structure identified here (as shown in Fig. 2) is based on the wind speed spin-up vortex profile which is integrated $6 \mathrm{~h}$ after the model initiation, not the initial wind profile based on the vortex structure parameters. Wu et al. (2012) proposed a vortex initialization method to construct the vortex structure based on ensemble Kalman filter data assimilation. In that method the observed vortex structure could be assimilated to the model at the initial time and the vortex structure could be maintained for several hours. A follow-up study based on this ensemble Kalman filter data assimilation framework will be applied to assess the vortex structure impact on the influence of eyewall evolution and topography.

\section{RESULTS}

\subsection{Model Verification of the BMR Experiment}

In this section we will show the simulated track, intensity evolution, eyewall structure and precipitation distribution of Sinlaku in the BMR simulation, which are in reasonable agreement with the observations. The BMR experiment simulation track and intensity evolution are shown in Figs. 3 and 4, respectively. Although the BMR track is not closest to the JTWC best track before landfall, it is still the best simulation in comparison with the rest of the experiments in this study. Due to the well-simulated landfall process in the BMR experiment, its intensity evolution is closest to the JTWC analysis. Figure 5 shows the horizontal reflectivity verification $24 \mathrm{~h}$ before landfall, during landfall, and after leaving Taiwan, respectively. In both the observed and simulated reflectivities, the northwestern side of the TC had relatively high reflectivity before landfall (Figs. 5a, b). This result suggests that the channel effect and the localized heavy rainfall at the northeastern side of Taiwan was produced partly due to the orographic effect associated with the outer TC circulation, in addition to the fact that rainfall accompanying the TC itself was as near as the eyewall, which will be discussed in section 4.3. At landfall the TC structure became asymmetric because the western side of the TC was destroyed by the terrain (Figs. 5c, d). However, the outer circulation induced intense reflectivity on the Central Mountain Range, which appeared on both the model and the TC observations. The TC eye cannot be found clearly in Fig. 5c due to the friction effect of the topography. Figure $5 d$ shows that the translation speed of the simulated TC is slower than that of the observed TC. In general, the observed and simulated reflectivities are similar to each other (Figs. 5c, d), but different in the inner core caused by different TC center positions during the landfall period. After reentering the ocean the observed TC structure was almost disintegrated due to the orographic effects (Fig. 5e), but intense reflectivity of about $50 \mathrm{dBZ}$ was still maintained on the Central Mountain Range. The simulated TC moves faster than the observed TC, thus the simulated storm has already left Taiwan at this time and the outer convection reorganization is shown in 
Table 2. Description of the terrain sensitivity experiments. The $\mathrm{V}_{\max }$ is the maximum tangential wind, $\mathrm{R}_{\max }$ is the radius of maximum tangential wind, $\alpha$ is the decay coefficient of tangential wind.

\begin{tabular}{|c|c|c|c|c|}
\hline Experiment & Description & $\mathbf{V}_{\max }\left(\mathbf{m ~ s}^{-1}\right)$ & $\mathbf{R}_{\max }(\mathbf{k m})$ & $\alpha$ \\
\hline CTL & Control run (full terrain, without vortex bogusing) & None & None & None \\
\hline BMR & Full terrain run (full terrain, with vortex bogusing) & 65 & 40 & 0.2 \\
\hline FLAT & Flattened terrain run (1-m height of Taiwan topography, with vortex bogusing) & 65 & 40 & 0.2 \\
\hline SEA & Ocean run (The terrain of Taiwan is replaced to ocean, with vortex bogusing) & 65 & 40 & 0.2 \\
\hline $\mathrm{T} 130$ & $\begin{array}{l}\text { Higher terrain run (The terrain of Taiwan is multiplied to } 1.3 \text { times of original value, } \\
\text { with vortex bogusing) }\end{array}$ & 65 & 40 & 0.2 \\
\hline
\end{tabular}

Table 3. Same as Table 2, but for the vortex structure sensitivity experiments.

\begin{tabular}{c|ccccc}
\hline Experiment & Description & Size of vortex bogusing $(\mathbf{k m})$ & $\mathbf{V}_{\max }\left(\mathbf{m ~ s}^{-1}\right)$ & $\mathbf{R}_{\max }(\mathbf{k m})$ & $\boldsymbol{\alpha}$ \\
\hline BSR & Vortex bogusing with a small eye radius & 150 & 65 & 30 & 0.2 \\
BMR & Vortex bogusing with a medium eye radius & 200 & 65 & 40 & 0.2 \\
BLR & Vortex bogusing with a large eye radius & 250 & 65 & 60 & 0.2 \\
\hline
\end{tabular}

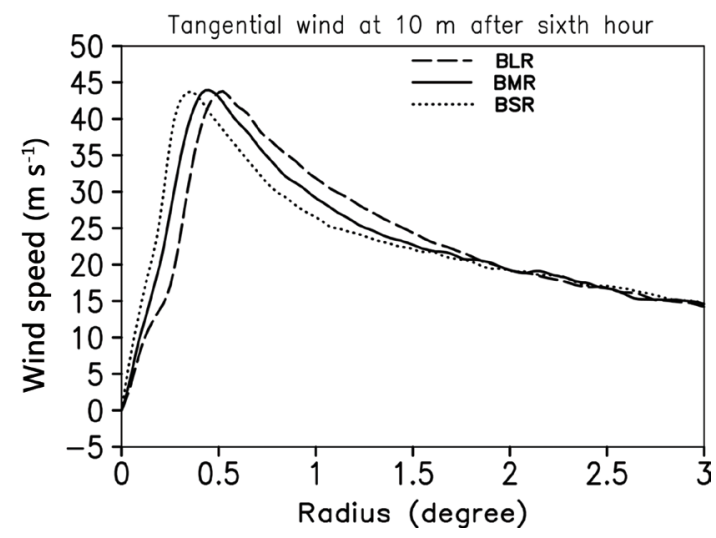

Fig. 2. Comparisons of initial vortex structure at different maximum wind radius. The lowest-layer $(\sigma=0.9965)$ azimuthal tangential wind after $6 \mathrm{~h}$ of model integration, unit is $\mathrm{m} \mathrm{s}^{-1}$.
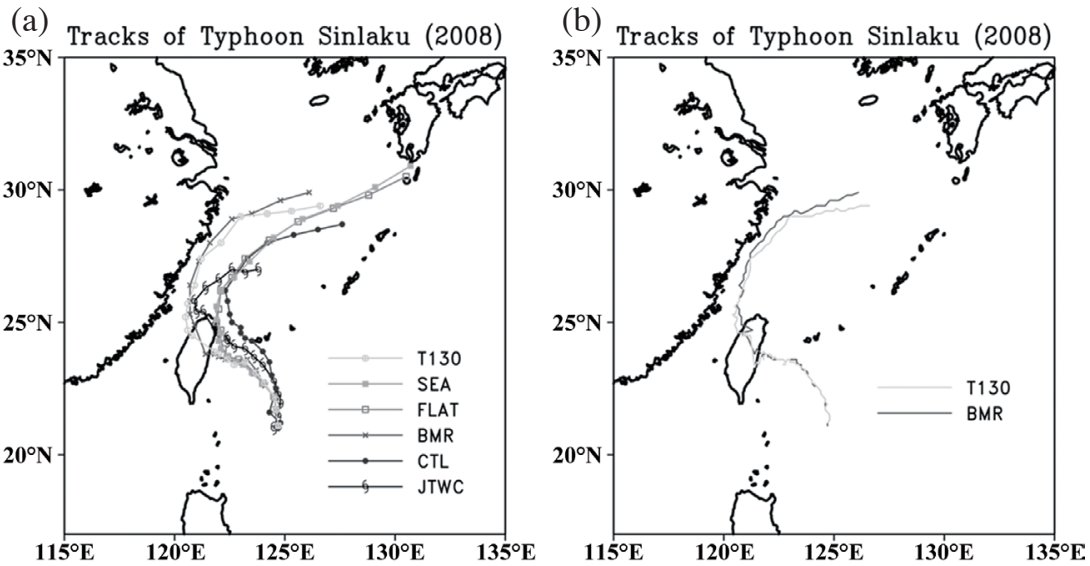

Fig. 3. (a) The JTWC best track and simulated tracks of terrain sensitivity experiments for Typhoon Sinlaku, tracks are plotted every 6 h; (b) the hourly simulated tracks of T130 and BMR experiment. The simulated storm center is defined by the location of the minimum vertically averaged geopotential height between 900 and $700 \mathrm{hPa}$. 


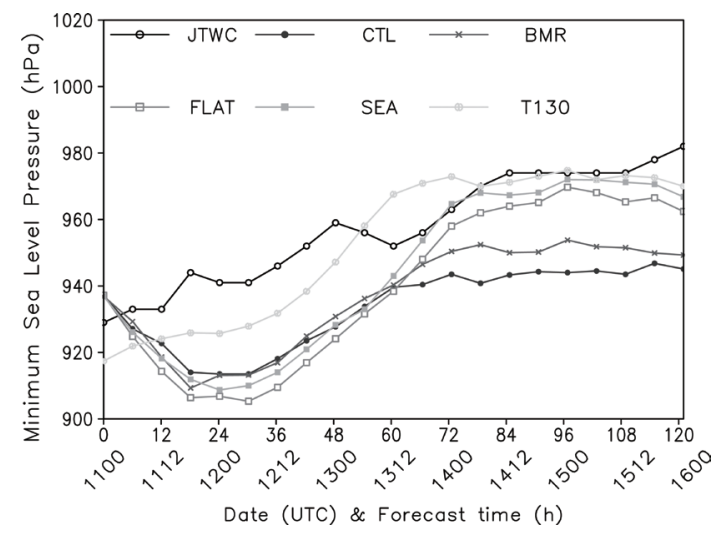

Fig. 4. Time series of minimum sea level pressure (SLP) of JTWC best track and those from terrain sensitivity experiments, unit is $\mathrm{hPa}$.

(a)

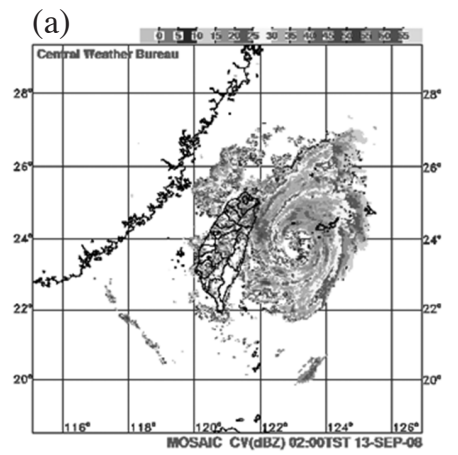

(c)

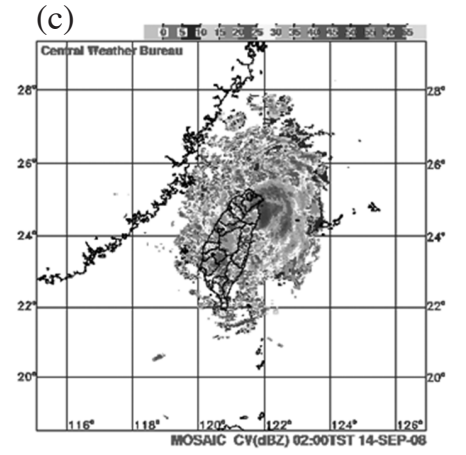

(e)

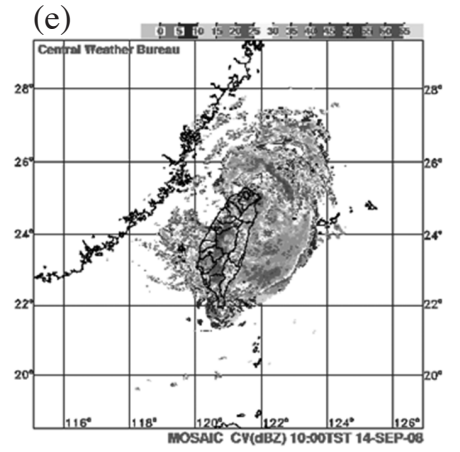

(b)

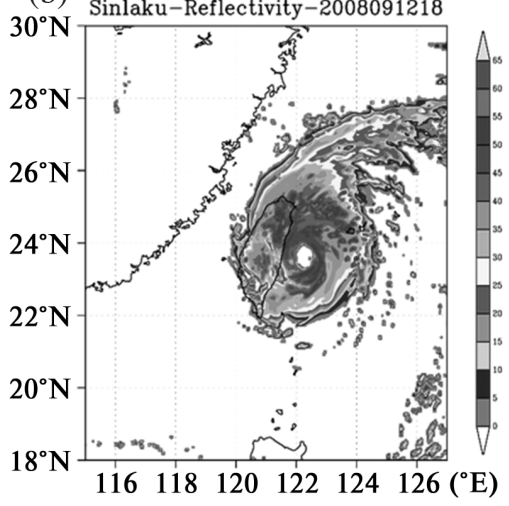

(d)

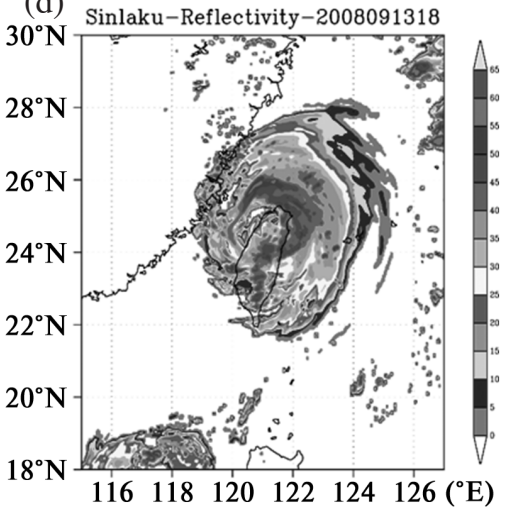

(f)

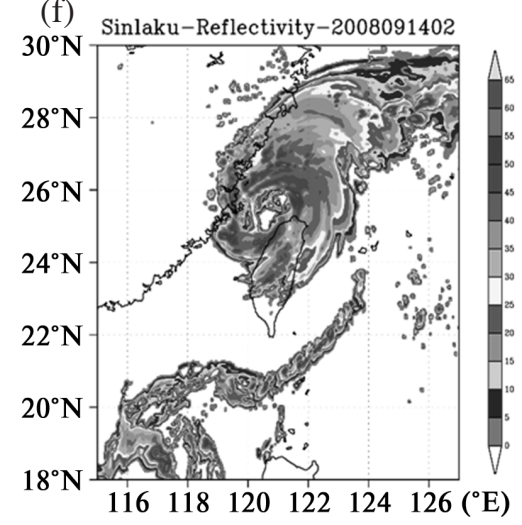

Fig. 5. A composite of the observed vertical maximum radar reflectivity at (a) 0200 LST 13 September 2008; (c) 0200 LST 14 September 2008; (e) 1000 LST 14 September 2008, and the simulated vertical maximum reflectivity of BMR experiment at (b) 0200 LST 13 September 2008; (d) 0200 LST 14 September 2008; (f) 1000 LST 14 September 2008. Unit of reflectivity is dBZ. 
Fig. 5f. According to Figs. 5c - $\mathrm{f}$ the inner-eyewall breakdown during landfall and the outer eyewall reorganization are clearly revealed. These results are consistent with the observational study from Chou et al. (2011).

Comparisons of the observed and simulated rainfall at three periods ( $24 \mathrm{~h}$ before landfall, during landfall, $24 \mathrm{~h}$ after landfall) and the overall terrain influenced period when Typhoon Sinlaku was passing Taiwan are shown in Fig. 6. Comparing the rainfall pattern before the landfall stage (Figs. 6a, b), the observational data shows that higher rainfall areas were located over the windward side of the northern and central mountain areas of Taiwan. The model was able to capture the high precipitation locations, while it slightly overestimated the rainfall amount. At the landfall period stage (Figs. 6c, d) the observed higher precipitation area was shifted to the central and southern mountain areas of Taiwan. The model-simulated higher precipitation locations and amounts are very similar to the observed. For the leaving Taiwan storm stage (Figs. 6e,f) the observed higher precipitation areas are similar to those in the landfall stage. When the storm moves to the northwest part of Taiwan, the higher precipitation area expands to the northwestern coastline area of Taiwan. The model was able to simulate the precipitation pattern at this stage. Since the storm in the simulation moves away from Taiwan faster than the observed $\mathrm{TC}$, the precipitation amounts over the central and southern mountain areas were much less than the observed. The overall precipitation comparison between observations and simulations during Sinlaku's passing over Taiwan can be found in Figs. $6 \mathrm{~g}$ and $\mathrm{h}$. The observed higher rainfall areas were located over the Central Mountain Range and northern part of Taiwan. Furthermore, the rain shadow over the southeast part of Taiwan can be clearly observed. The model did capture the major precipitation areas and rain shadow areas quite well for Sinlaku. This result demonstrates that the model can reproduce and capture precipitation distribution well during the period when Sinlkau was passing over Taiwan. Note that the major differences between the simulated and observed rainfall at some periods are due to the fact that the translation speed of the simulated storm is much faster than the observed speed and that the landfall location is slightly deviated to the south.

\subsection{Sensitivity of Terrain}

To further understand the eyewall evolution phenomena for TCs passing Taiwan it is necessary to investigate these processes with model simulations. The land use and terrain height effects could be easily investigated by comparing the results from terrain sensitivity experiments. Figure $3 \mathrm{a}$ shows the simulated tracks of five experiments and the analyzed best-track from JTWC. The storm location is defined as the position of the minimum vertically averaged geopotential height between 700 - $900 \mathrm{hPa}$. Ex- cept for the CTL experiment all simulated tracks headed northwestward before the TC made landfall and then turned northeastward after landfall. The simulated tracks are in general faster than the best track because the looping track before the storm made landfall was not well simulated by the model. In the BMR and T130 experiments, the simulated storms made landfall on central Taiwan, while in the FLAT and SEA experiments the storms made landfall over the northern part of Taiwan. When comparing the tracks in the BMR and T130 experiments (Fig. 3b) it is clear that the southward-deflection track is more obvious under higher terrain conditions. These results indicate that the existence of topography could lead the model to present a southward track deflection when the storm approached Taiwan. Overall, the terrain sensitivity experiment simulated tracks in this study are consistent with the findings revealed by Jian and Wu (2008) and Hsu et al. (2013). Because the main purpose of this study is to discuss the eyewall evolution influenced by the topography, a detailed analysis about track deflection will not be investigated. Note that this study is conducted in a real-case framework. A change in terrain condition can further influence the steering flow of the storm, thus change the track in the simulations. Therefore, it is suggested that more insights into the track deflection mechanisms induced by topography could be obtained from more well-designed idealized numerical models.

The time series for the minimum sea level pressure (SLP) for four experiments and JTWC analysis are also shown in Fig. 4. In the CTL experiment the initial intensity is much weaker than in the JTWC analysis, and the storm gradually intensified at the beginning of the forecast period and retained its intensity later on. Due to the well-simulated landfall process in the BMR experiment, its intensity evolution is closer to the JTWC analysis. The intensity in the T130 experiment is more reduced than in BMR, indicating that the higher mountains could weaken the storm intensity faster. It can be found that the intensity difference between BMR and T130 experiments starts from hour $18 \mathrm{~h}$ and the intensity difference becomes larger before the storm made landfall. This result implies that the higher mountains could weaken the strength of the outer circulation and then decrease the moisture convergence to fuel the storm, thus reduce the storm intensity. The slightly decreased intensity of the FLAT and SEA experiments is because the terrain effect is reduced, or removed, in these experiments. The intensity in FLAT is further reduced than in the SEA, indicating that the moisture supply cutoff from the ocean could lead to storm weakening.

The radius-time Hovmöller diagrams for the azimuthally-averaged tangential wind from the five full physics experiments (Fig. 7) indicate that the eyewall breakdown and reformation for Sinlaku are closely related to the influence of the various underlying surfaces. In the CTL experiment (Fig. 7a), the storm gradually intensifies from a weak vortex 
SINLAKU rainfall in 2008/09/1302-1402 LST

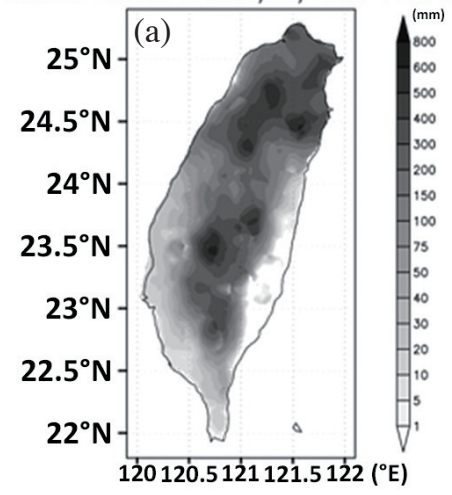

SINLAKU rainfall in 2008/09/1402-1410 LST

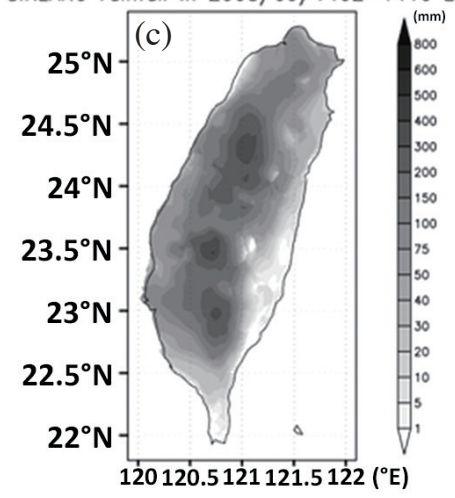

SINLAKU rainfall in 2008/09/1410-1510 LST

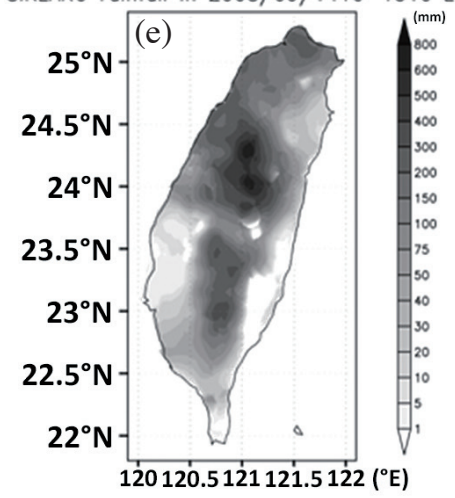

SINLAKU rainfall in 2008/09/1302-1510 LST

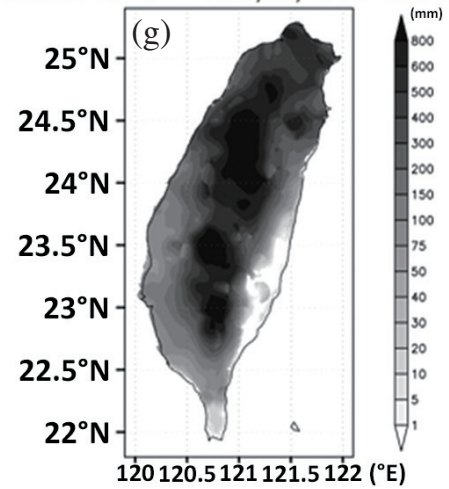

WRF rainfall in 2008/09/1302-1402 LST

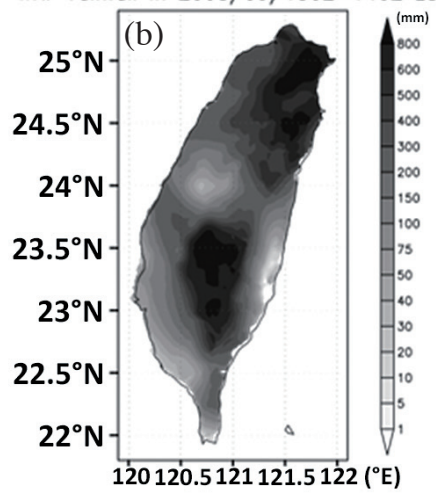

WRF rainfoll in 2008/09/1402-1410 LST

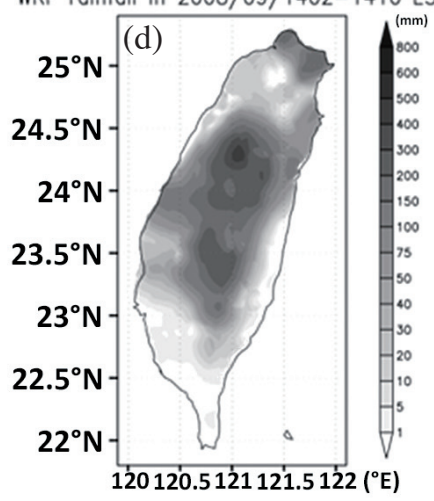

WRF rainfoll in 2008/09/1410-1510 LST

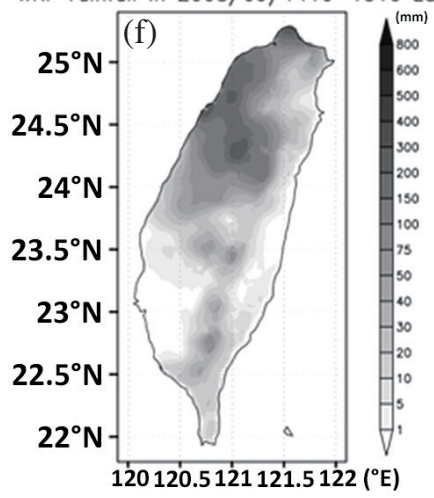

WRF roinfoll in 2008/09/1302-1510 LST

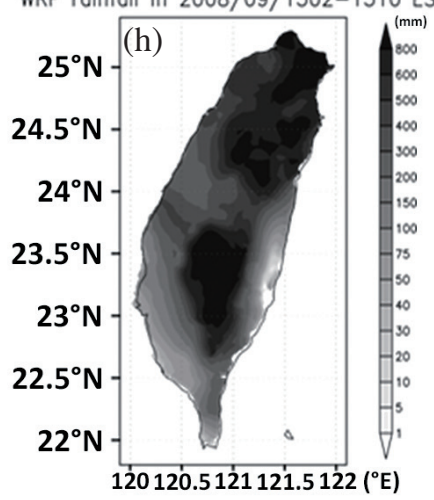

Fig. 6. Horizontal distribution of accumulated rainfall (mm) over Taiwan from the observations (left panels) and BMR experiment (right panels) during (a), (b) $24 \mathrm{~h}$ before landfall, 0200 LST 13 September 2008 - 0200 LST 14 September 2008; (c), (d) landfall period, 0200 LST 14 September 2008 - 1000 LST 14 September 2008; (e), (f) 24 h after leaving, 1000 LST 14 September 2008 - 1000 LST 15 September 2008; (g), (h) terrain influenced period, 0200 LST 13 September 2008 - 1000 LST 15 September 2008. 

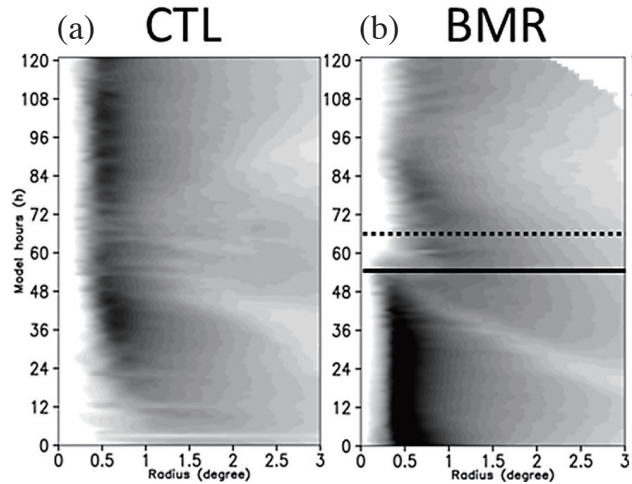

(c) T130

(d) FLAT

(e) SEA

Fig. 7. Radius-time Hovmöller diagram of azimuthally averaged tangential wind ( $\mathrm{m} \mathrm{s}^{-1}$ ) at $\sigma=0.9965$ for (a) CTL, (b) BMR, (c) T130, (d) FLAT, and (e) SEA. The solid (dashed) line indicates the time when Sinlaku made landfall at (exited from) Taiwan. The model data is from mesh 3 (3.3 km resolution), and the output interval is one hour.

into a strong vortex and does not make landfall. The eyewall contraction starts from the beginning of the simulation and reaches a steady state with an $R_{\max }$ of 0.7 degree-latitude. In the BMR experiment (Fig. 7b) the main eyewall contraction, breakdown and reformation process features during the period when Sinlaku made landfall are well captured. The eyewall was gradually affected by the topography during hours 36 - 48. The inner-core wind maximum decreases and the outer-core wind maximum forms and increases. The inner-core wind maximum vanishes and the outer wind maximum replaces the inner wind maximum around hour 54 . The maximum wind strength then gradually increases and the maximum wind radius contracts again until hour 84 . This eyewall evolution phenomenon is also shown in the T130 experiment (Fig, 7c) except that the strength of the outer wind maximum is much weaker than in the BMR run. The eyewall evolution is not obvious in the FLAT run (Fig. 7d). The inner wind maximum decreases strength slightly and expands outward when the storm passes through the $1-\mathrm{m}$ height terrain. In the SEA experiment (Fig. 7e) the eyewall evolution is not shown in the simulation. The inner wind maximum maintains its strength and gradually expands outward because the storm moves northward and encounters a mid-latitude trough system.

Figure 8 shows the radius-time Hovmöller diagrams for azimuthally averaged surface rainfall rate analyses. The results are consistent with the results from the lowest level tangential wind analyses. The major rainfall areas of the CTL run gradually contract to the inner-core of the storm with time (Fig. 8a). This is because that storm does not make landfall in the CTL run and the variations in the rainfall area is not obvious. However, the rainfall area contraction before landfall could be found using the variation in high rainfall rate areas in the BMR and T130 simulations (Figs. $8 \mathrm{~b}, \mathrm{c}$ ). The high rainfall rate areas then change from the inner core to outer core after landfall, which is caused by the breakdown of the inner eyewall and reformation of the outer eyewall. The variations in the rainfall pattern for the FLAT and SEA runs also reveal a persistent inner core rainfall pattern expansion (Figs. 8d, e), which is consistent with the results shown in Figs. 7d, e.

The above tangential wind terrain sensitivity experiment analyses are similar with the findings in the numerical simulations of $\mathrm{Wu}$ et al. $(2003,2009)$. They conducted model simulations to assess the role of Luzon Island and adiabatic processes in affecting the eyewall evolution of Typhoon Zeb (1998). The rainfall analyses discussed in this section are also consistent with the observational analyses proposed by Chou et al. (2011). This study demonstrates again that the topography plays a dominating factor in affecting the eyewall evolution and that the area with high tangential wind and rainfall associated with the storm expand outward when the storm passes the terrain.

\subsection{Sensitivity Experiment of Vortex Structure}

In this section the $\mathrm{R}_{\max }$ sensitivity simulation experiments that implanted different vortex structures are discussed. The BSR, BMR, and BLR experiments represent the vortex structures with small, medium and large eyewall radii, respectively (as shown in Fig. 2a). Figure 9a shows the track simulations for three experiments. Overall, the tracks among the three experiments are very similar. The landfall and recurvature track are also simulated. The storms take about $12 \mathrm{~h}$ to pass the island in the three experiments. Note that the landfalling position in the BSR simulation is a little northward compared to those in the BMR and BLR experiments. Figure $9 \mathrm{~b}$ shows the minimum SLP time series of three $\mathrm{R}_{\max }$ sensitivity experiments. Alhough the initial BSR intensity is larger than that in the BMR and BLR, the tangential wind speeds are the same. Furthermore, the simulated model storm with smaller eyewall exhibits stronger intensity than those with larger eyewalls at the incipient time. The decreasing intensity is also obvious during the landfall period. This may be because the proportion of small-eyewall vortex affected by terrain is greater than that for large eyewall vortices. 
Figure 10 shows the model-simulated horizontal maximum radar reflectivity and the rainfall rate during and after the landfall period for three $\mathrm{R}_{\max }$ sensitivity experiments. The radar reflectivity is plotted at $6 \mathrm{~h}$ after the storm made landfall. The rainfall rate is time-averaged from $3-9 \mathrm{~h}$ after the storm made landfall. Note that because the landfall time in the three experiments is different, the plotted time shown in the panels is adjusted accordingly. During the landfall period the strong convective BSR regions appear as a broken shape (Fig. 10a), but those in the BMR and BLR are much stronger and have a symmetrical structure (Figs. 10b, c). Note that the area with high reflectivity (>20 dBZ) in BLR is larger than that in BMR, which implies that the vortex with smaller eyewall is obviously destroyed by the terrain. During the landfall period the rainfall over the northern and southern part of Taiwan in BSR is much less than that in BMR and BLR. Note that the local maximum rainfall amount could be shown over the northeastern coastline area in the BSR experiment, which is induced by the heavy precipitation rate around the eyewall. (cf. Figs. 10d, e, f). The difference in precipitation intensity and distribution be- tween the BMR and BLR is small (Figs. 10e, f). The lower panels in Fig. 10 are the simulated radar reflectivity for $12 \mathrm{~h}$ after the storm leaves Taiwan and the time-averaged rainfall rate $9-15 \mathrm{~h}$ after the storm exits Taiwan. The area with high reflectivity in BLR is still larger than the same areas in the other experiments, especially for the strong convective rain bands over the northern part of Taiwan (Figs. 10g, h, i). Based on the average rainfall rate comparisons for the three experiments (Figs. 10j, k, l), the wider precipitation areas, which were located in the northern part of the storm in the northern part of Taiwan, can be shown in the larger eyewall experiment. In other words, the storm with larger eyewall would induce broader and more precipitation as the vortex approached Taiwan.

Figure 11 shows the Hovmöller diagram of the azimuthally averaged tangential wind at the low level for three $\mathrm{R}_{\max }$ sensitivity experiments. The eyewall evolution phenomenon is clearly shown in the three experiments. The inner-core wind maximum broke down and the outer-core wind maximum formed when the storm was influenced by the topography. The outer-core wind maximum in BLR is

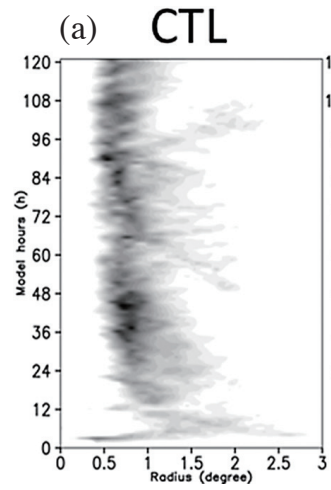

(b) BMR

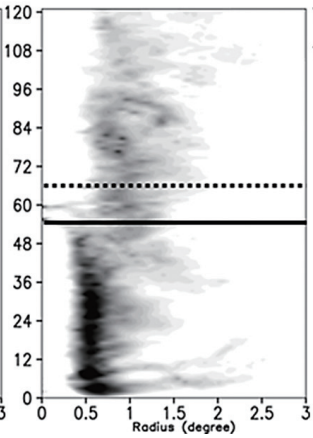

(c) T130

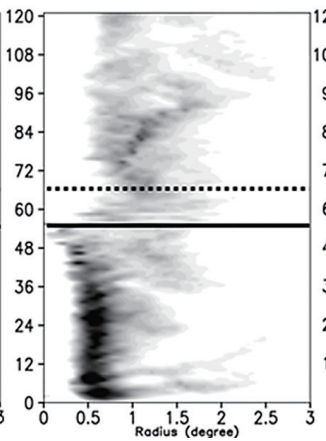

(d) FLAT

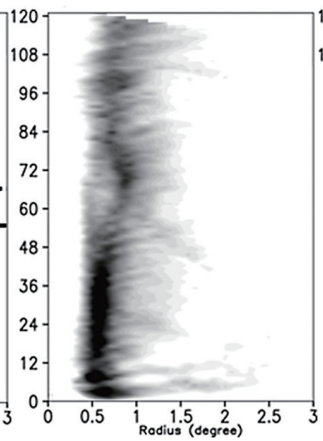

(e) SEA

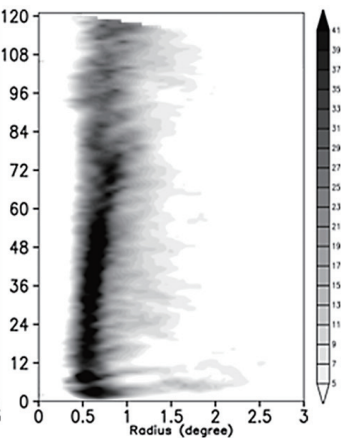

Fig. 8. Same as Fig. 7, but for the simulated surface rainfall rate $\left(\mathrm{mm} \mathrm{h}^{-1}\right)$.

(a) Tracks of Typhoon Sinlaku (2008)

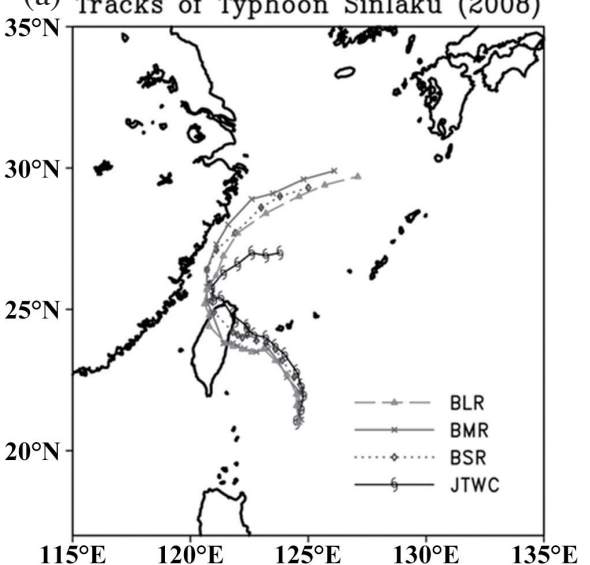

(b)

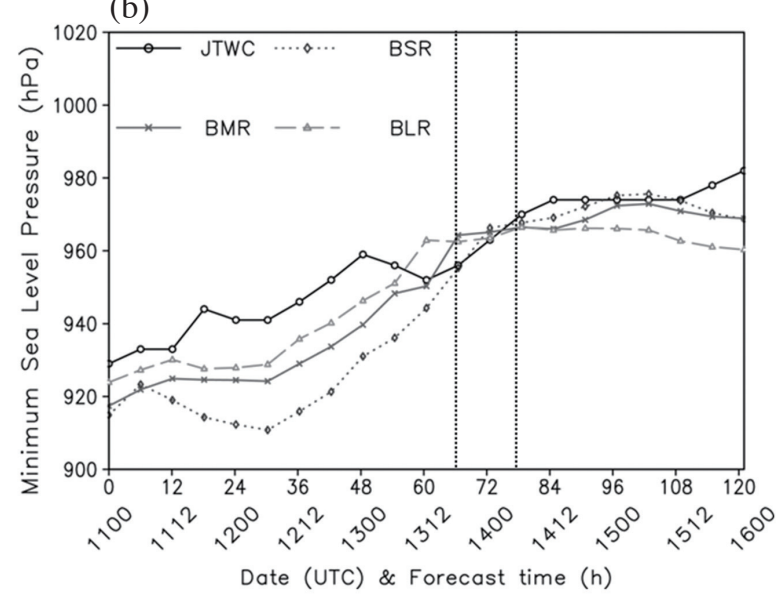

Fig. 9. (a) The JTWC best track and simulated tracks of $\mathrm{R}_{\max }$ sensitivity experiments; (b) time series of minimum SLP of JTWC best track and those of $R_{\max }$ sensitivity experiments. The left (right) vertical dashed line indicates the time when Sinlaku made landfall at (left) Taiwan. 

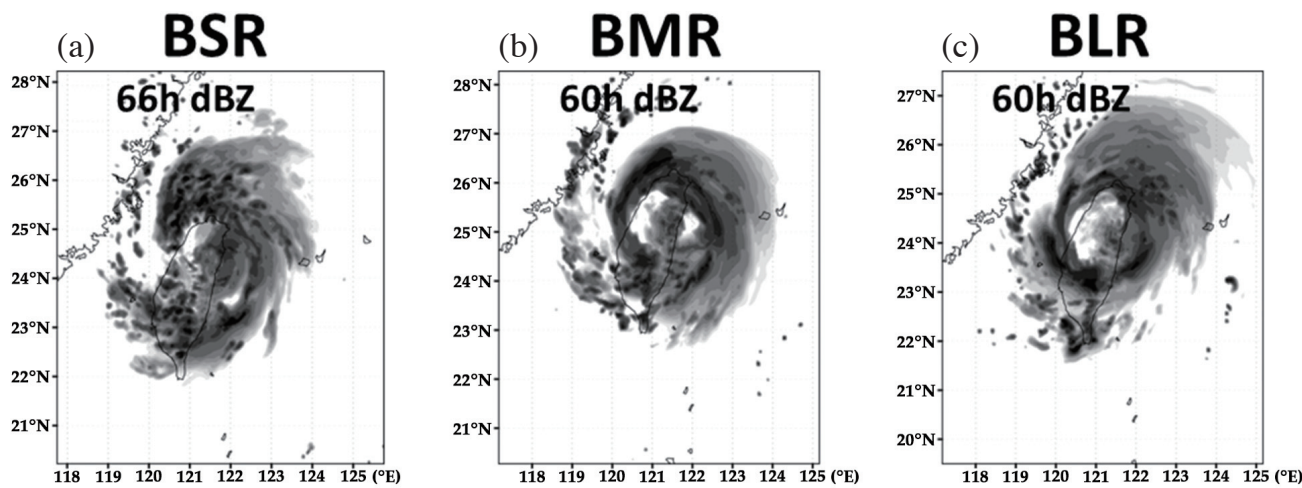

(d)

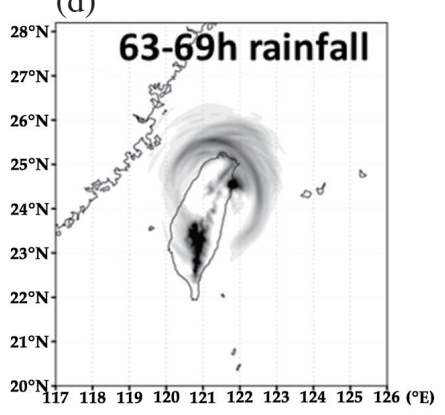

(g)
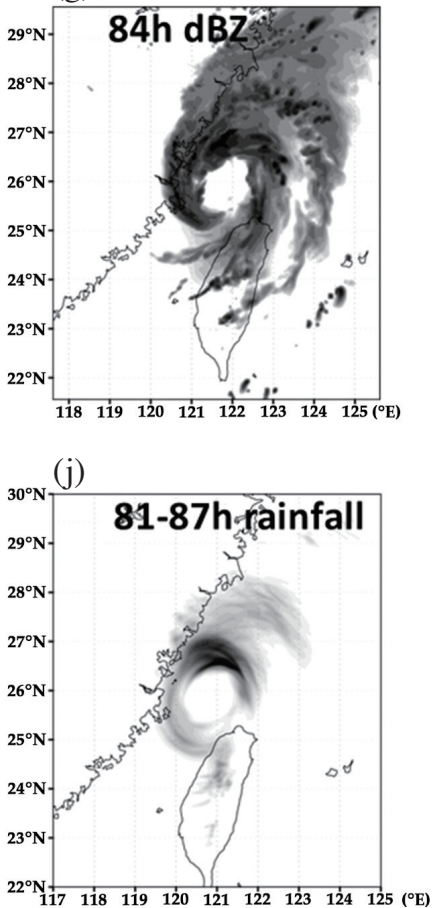

(e)

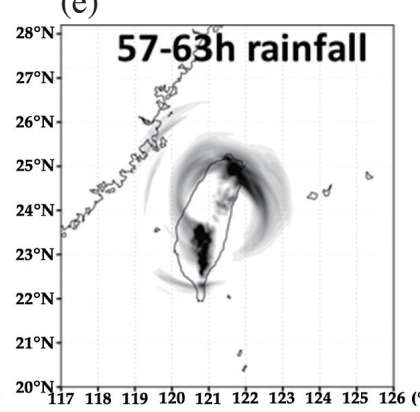

(h)
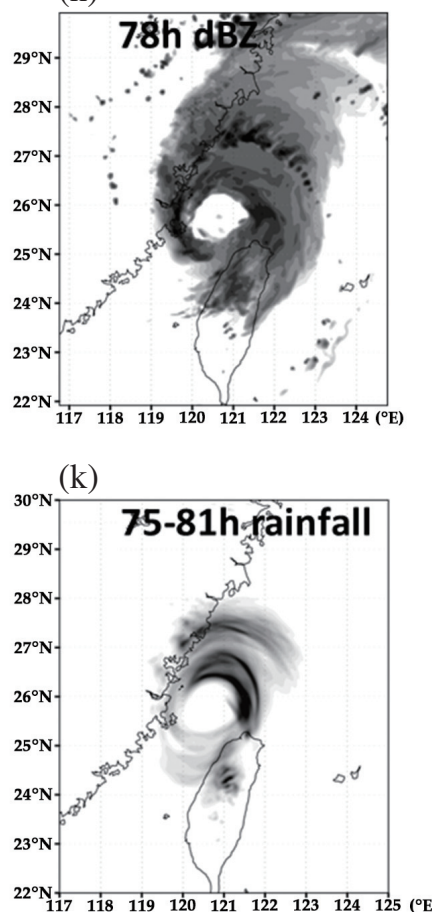

(f)

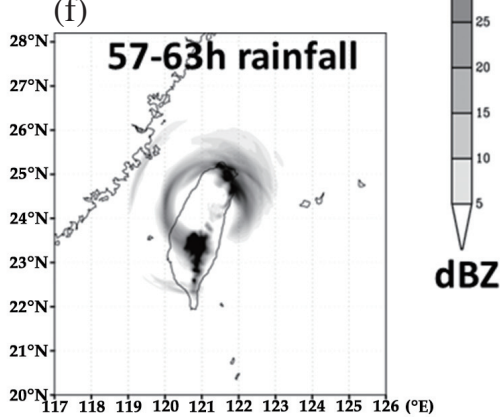

(i)
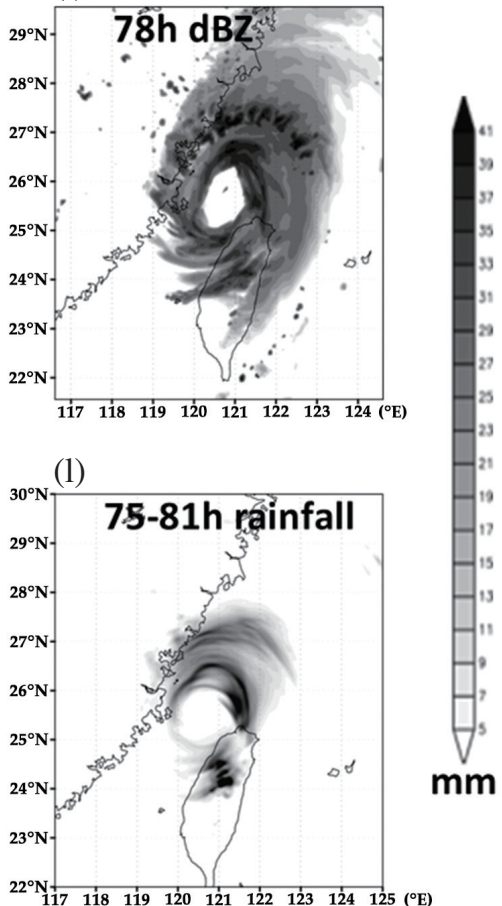

Fig. 10. The lowest-level $(\sigma=0.9965)$ radar reflectivity $(\mathrm{dBZ})$ and averaged surface rainfall rate $\left(\mathrm{mm} \mathrm{h}^{-1}\right)$ in (a), (d), (g), (j) BSR; (b), (e), (h), (k) BMR; (c), (f), (i), (l) BLR. The simulation times are shown in the upper-left corner of each image. 

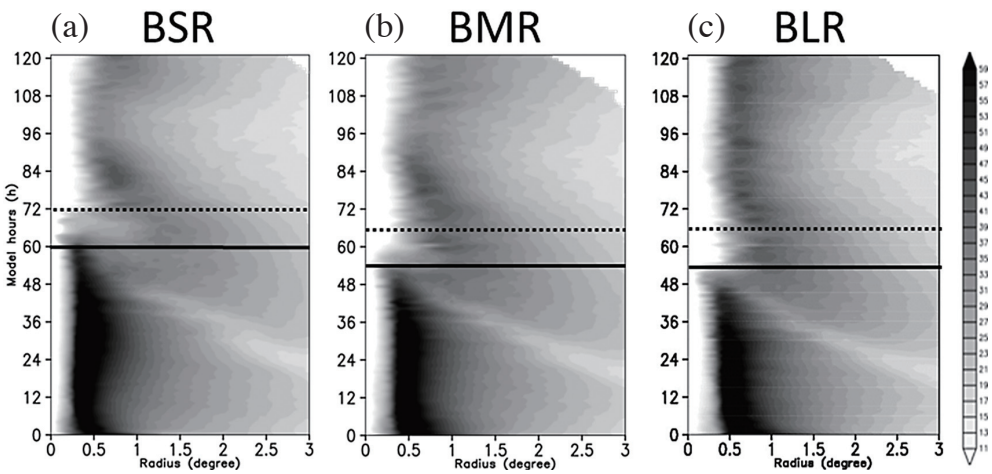

Fig. 11. Radius-time Hovmöller diagram of azimuthally averaged tangential wind $\left(\mathrm{m} \mathrm{s}^{-1}\right)$ at low level $(\sigma=0.9965-0.9215)$ for $(a)$ BSR, $(b)$ BMR, and (c) BLR. The solid (dashed) line indicates the time when model-simulated storms make landfall at (leave from) Taiwan. The model data is from mesh 3 (3.3 km resolution), and the output interval is one hour.

stronger than the one in BSR and BMR during the terraininfluenced period. The terrain-influenced period is defined by the time $12 \mathrm{~h}$ before storm landfall and $12 \mathrm{~h}$ after the storm left Taiwan. The surface rainfall rate analysis also reveals similar results during the terrain-influenced period (Fig. 12). The surface rainfall rate in BLR is much larger and wider than those in the BMR and BSR experiments.

In order to quantify the difference among the three $\mathrm{R}_{\max }$ sensitivity experiments, the temporally- and azimuthallyaveraged tangential wind and rainfall rate were calculated in the terrain-influenced period. Figure 13a shows the temporally- and azimuthally-averaged tangential wind during the terrain-influenced period for three experiments. The vortex with larger eyewall (i.e., BLR) possesses stronger tangential wind speed around the eyewall (0.5 - 1.7 degree-latitude from the center), and the BMR result is similar to that of BLR. The time and azimuthal radial wind average is consistent with the tangential wind field result (Fig. 13b). Comparing these three experiments the vortex with larger eyewall reveals stronger radial inflow over the outer storm radii. Analysis of the time and azimuthal surface rainfall rate average shows that the vortex with larger eyewall could induce more rainfall over the outer part of the storm. Note that these three simulations possess the same terrain condition, but the rainfall result over the storm outer-core $(0.5$ - 1.4 degreelatitude from the center) is obviously different.

Through sensitivity experiments using different vortex structures we have shown that the storm with larger eyewall radius tends to induce stronger wind and rainfall at the outer part of the storm during the terrain-crossing period. The physical explanation for these results is that the storm with larger eyewall has the stronger wind field extending farther outward from the storm center (cf. Fig. 2), thus it could produce more precipitation over the outer part of the storm.

\section{CONCLUSIONS}

A nested WRF model with the finest grid size of $3.3 \mathrm{~km}$ was employed to investigate the eyewall structure of Typhoon Sinlaku. The focal points of this study pertain to the topographic effects on eyewall contraction before landfall, breakdown and reformation after landfall. The terrain condition and vortex structure effects were examined. In order to produce a reasonable typhoon structure with well-adjusted intensity and structure, the bogused-vortex implantation method was applied in this study.

Based on the results from terrain sensitivity experiments, it appears that the southward-deflection track is more obvious when higher terrain exists in the model. This result implies that the existence of the topography could lead a southward track deflection when the storm approached Taiwan, which is consistent with the findings revealed by Jian and $\mathrm{Wu}$ (2008) and Hsu et al. (2013). The Hovmöller diagram analyses of surface tangential wind terrain sensitivity experiments show that the eyewall evolution appears only in experiments with full and higher terrain topography. This result indicates that the terrain plays a key role in this eyewall evolution phenomenon, which had been discussed in the numerical simulations of Wu et al. $(2003,2009)$. The rainfall analyses discussed in this study are also consistent with the observational analyses proposed by Chou et al. (2011). This study demonstrates again that the topography plays a dominating factor affecting the eyewall evolution and the area with high tangential wind, and that the rainfall associated with the storm expands outward when the storm passes the terrain.

The vortex structure experimental results suggest that the track and intensity evolution are slightly influenced by the vortex structure at the initial time. The landfalling position in the experiment with smaller eyewall vortex is a little northward when compared to those with larger eyewalls. The simulated storm with smaller eyewall exhibited stronger intensity than those with larger eyewalls before the storm made landfall, and decreasing intensity is also obvious during the landfall period. The horizontal convective structure and precipitation pattern during the terrain-influenced period seem to be related to the vortex structure. The storm with a 
(a) BSR

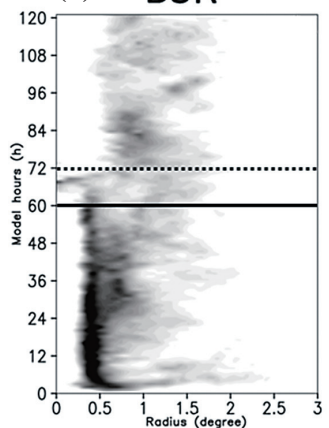

(b) BMR

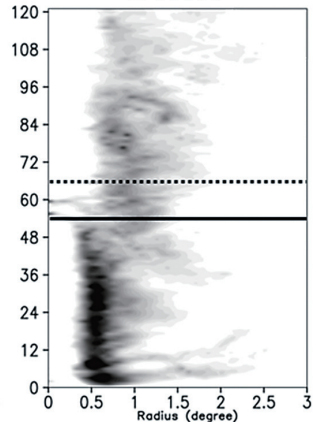

(c) BLR

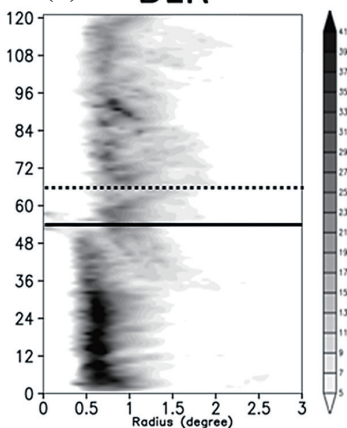

Fig. 12. Same as Fig. 11, but for the simulated surface rainfall rate $\left(\mathrm{mm} \mathrm{h}^{-1}\right)$.
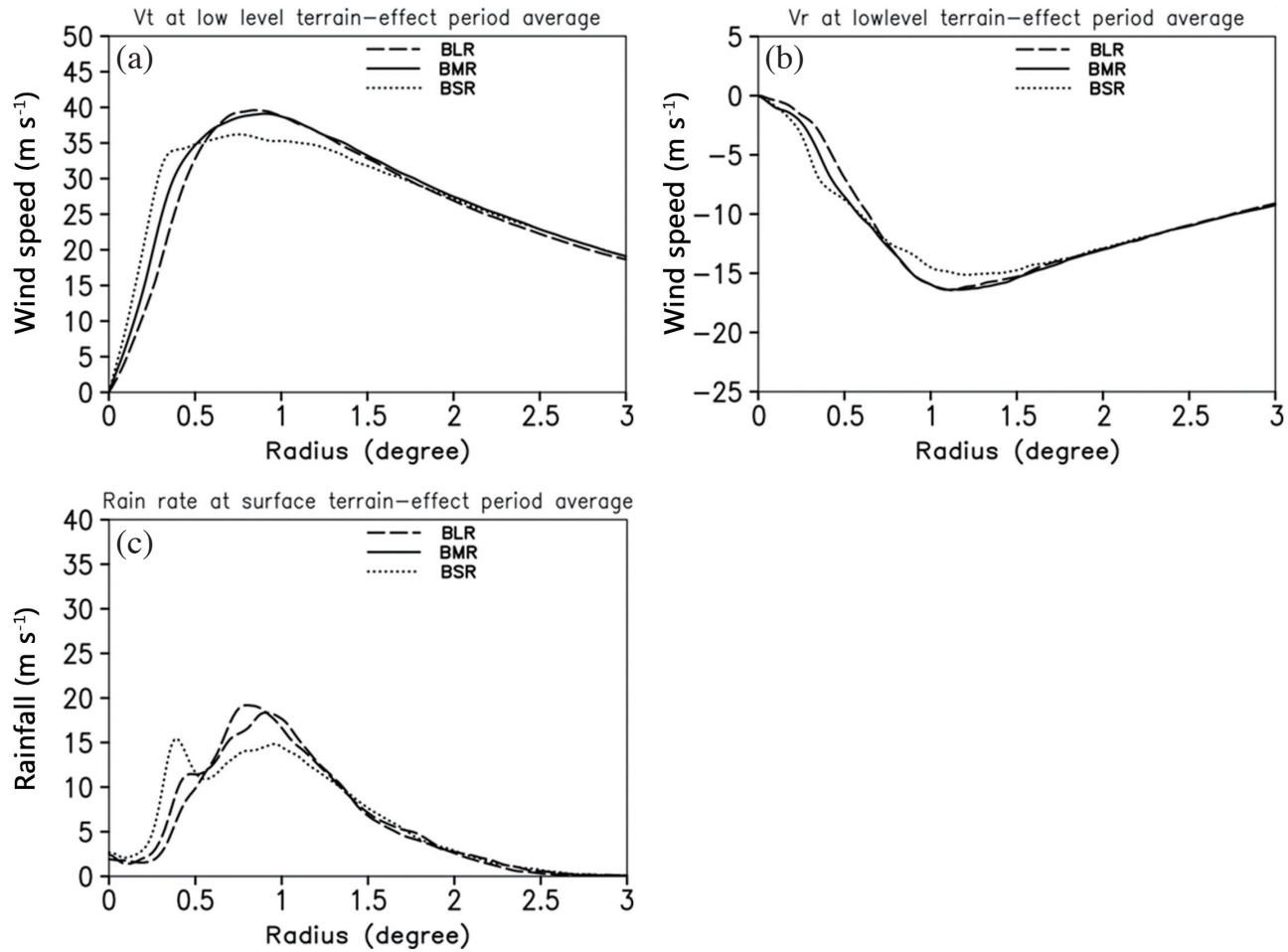

Fig. 13. The time and azimuthal average of (a) tangential wind $\left(\mathrm{m} \mathrm{s}^{-1}\right)$ as a function of radius (in degree-latitude) from the vortex center at low level $(\sigma=0.9965-0.9215)$; (b) radial wind $\left(\mathrm{m} \mathrm{s}^{-1}\right)$; and (c) surface rainfall rate $\left(\mathrm{mm} \mathrm{h}^{-1}\right)$ for $\mathrm{R}_{\max }$ sensitivity experiments. The time averaged is calculated in terrain-influenced period.

larger eyewall tends to maintain its convective structure and induce more precipitation inside the inner storm core.

In order to quantify the difference among the three $\mathrm{R}_{\max }$ sensitivity experiments, the temporally- and azimuthallyaveraged tangential wind and rainfall rate were calculated in the terrain-influenced period. The results showed that the vortex with a larger eyewall could maintain the stronger tangential wind speed around the eyewall, and thus induce more rainfall outside the eyewall with less rainfall inside the eyewall. This result suggests that the vortex with larger angular momentum is more favorable to reform a new eyewall from the outer rainband contraction after it was affected by ter- rain. This result might be in line with the disaster caused by Typhoon Morakot (2009), which brought immense rainfall from the outer storm circulation. This was because Morakot was formed from a monsoon gyre system, characterized by a vortex with a larger eyewall size and outer wind strength (Ge et al. 2010).

Note that because of the limitation of the bogused vortex implantation method applied in this study, the sensitivity experiments regarding the vortex size and vortex strength could not be well addressed in the current framework. We tested various vortex strength experiments, but the model could not maintain the specified strength and structure at 
the beginning of the simulation. Wu et al. (2012) proposed a vortex initialization method to construct the vortex structure based on ensemble Kalman filter data assimilation. A follow-up study based on this ensemble Kalman filter data assimilation framework will be applied to assess the vortex structure impact on the eyewall evolution and topography. It is suggested that more insights into the eyewall evolution induced by topography could be obtained from better designed sensitivity numerical experiments with high-resolution cloud-resolving models.

Acknowledgements This work is supported by the National Science Council of Taiwan through Grants NSC-1012119-M-034-001 and NSC-102-2119-M-034-001.

\section{REFERENCES}

Chan, J. C. L., 2012: Recent studies on changes in track and convection associated with tropical cyclone landfall. Trop. Cyclone Res. Rev., 1, 33-40, doi: 10.6057/2012TCRR01.04. [Link]

Chan, K. T. F. and J. C. L. Chan, 2012: Size and strength of tropical cyclones as inferred from QuikSCAT data. Mon. Weather Rev., 140, 811-824, doi: 10.1175/ MWR-D-10-05062.1. [Link]

Chen, D. Y. C., K. K. W. Cheung, and C.S. Lee, 2011: Some implications of core regime wind structures in Western North Pacific tropical cyclones. Weather Forecast., 26, 61-75, doi: 10.1175/2010WAF2222420.1. [Link]

Chou, K. H. and C. C. Wu, 2008: Typhoon initialization in a mesoscale model-Combination of the bogused vortex and the dropwindsonde data in DOTSTAR.Mon. Weather Rev., 136, 865-879, doi: 10.1175/2007MWR2141.1. [Link]

Chou, K. H., C. C. Wu, and Y. Wang, 2011: Eyewall evolution of typhoons crossing the Philippines and Taiwan: An observational study. Terr. Atmos. Ocean. Sci., 22, 535548, doi: 10.3319/TAO.2011.05.10.01(TM). [Link]

Cocks, S. B. and W. M. Gray, 2002: Variability of the outer wind profiles of western north Pacific typhoons: Classifications and techniques for analysis and forecasting. Mon. Weather Rev., 130, 1989-2005, doi: 10.1175/152 0-0493(2002)130<1989:VOTOWP>2.0.CO;2. [Link]

Dudhia, J., 1989: Numerical study of convection observed during the winter monsoon experiment using a mesoscale two-dimensional model. J. Atmos. Sci., 46, 3077-3107, doi: 10.1175/1520-0469(1989)046<3077: NSOCOD $>2.0 . C O ; 2$. [Link]

Ge, X., T. Li, S. Zhang, and M. Peng, 2010: What causes the extremely heavy rainfall in Taiwan during Typhoon Morakot (2009)? Atmos. Sci. Lett., 11, 46-50, doi: 10.1002/as1.255. [Link]

Hsu, L. H., H. C. Kuo, and R. G. Fovell, 2013: On the geographic asymmetry of typhoon translation speed across the mountainous island of Taiwan. J. Atmos. Sci., 70 , 1006-1022, doi: 10.1175/JAS-D-12-0173.1. [Link]

Huang, C. Y., Y. H. Kuo, and W. Huang, 2002: Numerical simulations with MM5 3DVAR initialization. Terr. Atmos. Ocean. Sci., 13, 417-448.

Huang, C. Y., Y. H. Kuo, S. H. Chen, and F. Vandenberghe, 2005: Improvements in typhoon forecasts with assimilated GPS occultation refractivity. Weather Forecast., 20, 931-953, doi: 10.1175/WAF874.1. [Link]

Huang, Y. H., C. C. Wu, and Y. Wang, 2011: The influence of island topography on typhoon track deflection. Mon. Weather Rev., 139, 1708-1727, doi: 10.1175/2011MWR3560.1. [Link]

Jian, G. J. and C. C. Wu, 2008: A numerical study of the track deflection of Supertyphoon Haitang (2005) prior to its landfall in Taiwan. Mon. Weather Rev., 136, 598615, doi: 10.1175/2007MWR2134.1. [Link]

Kain, J.S. and J. M. Fritsch, 1993: Convective parameterization for mesoscale models: The Kain-Fritsch scheme. In: Emanuel, K. A. and D. J. Raymond (Eds.), The Representation of Cumulus Convection in Numerical Models, American Meteorological Society, 165-170.

Knaff, J. A., S. P. Longmore, and D. A. Molenar, 2014: An objective satellite-based tropical cyclone size climatology. J. Climate, 27, 455-476, doi: 10.1175/JCLI-D-1300096.1. [Link]

Lin, Y. L., S. Y. Chen, C. M. Hill, and C. Y. Huang, 2005: Control parameters for the influence of a mesoscale mountain range on cyclone track continuity and deflection. J. Atmos. Sci., 62, 1849-1866, doi: 10.1175/ JAS3439.1. [Link]

Liu, K. S. and J. C. L. Chan, 2002: Synoptic flow patterns associated with small and large tropical cyclones over the western north Pacific. Mon. Weather Rev., 130, 2134-2142, doi: 10.1175/15200493(2002)130<2134:SFPAWS>2.0.CO;2. [Link]

Low-Nam, S. and C. Davis, 2001: Development of a tropical cyclone bogussing scheme for the MM5 system. Preprint, 11th PSN/NCAR Mesoscale Model Users' Workshop, Boulder, CO, 130-134.

Merrill, R. T., 1984: A comparison of large and small tropical cyclones. Mon. Weather Rev., 112, 1408-1418, doi: 10.1175/1520-0493(1984)112<1408:ACOLAS>2.0.C O;2. [Link $]$

Mlawer, E. J., S. J. Taubman, P. D. Brown, M. J. Iacono, and S. A. Clough, 1997: Radiative transfer for inhomogeneous atmospheres: RRTM, a validated correlated-k model for the longwave. J. Geophys. Res., 102, 16663 16682, doi: 10.1029/97JD00237. [Link]

Noh, Y., W. G. Cheon, S. Y. Hong, and S. Raasch, 2003: Improvement of the K-profile model for the planetary boundary layer based on large eddy simulation data. Bound.-Layer Meteor., 107, 401-427, doi: 10.1023/A:1022146015946. [Link] 
Rogers, R., 2010: Convective-scale structure and evolution during a high-resolution simulation of tropical cyclone rapid intensification. J. Atmos. Sci., 67, 44-70, doi: 10.1175/2009JAS3122.1. [Link]

Rotunno, R. and K. A. Emanuel, 1987: An air-sea interaction theory for tropical cyclones. Part II: Evolutionary study using a nonhydrostatic axisymmetric numerical model. J. Atmos. Sci., 44, 542-561, doi: 10.1175/15200469(1987)044<0542:AAITFT>2.0.CO;2. [Link]

Skamarock, W. C., J. B. Klemp, J. Dudhia, D. O. Gill, D. M. Barker, M. G. Duda, X. Y. Huang, W. Wang, and J. G. Powers, 2008: A Description of the Advanced Research WRF Version 3. NCAR Technical Note, NCAR/TN-475+STR, National Center for Atmospheric Research Boulder, Colorado, USA, doi: 10.5065/ D68S4MVH. [Link]

Tao, W. K., J. Simpson, and M. McCumber, 1989: An icewater saturation adjustment. Mon. Weather Rev., 117, 231-235, doi: 10.1175/1520-0493(1989)117<0231:AIWSA $>2.0 . \mathrm{CO} ; 2$. [Link]

Wu, C. C., 2001: Numerical simulation of Typhoon Gladys (1994) and its interaction with Taiwan terrain using the GFDL hurricane model. Mon. Weather Rev., 129, 1533-1549, doi: 10.1175/1520-0493(2001)129<1533: NSOTGA $>2.0 . C O ; 2$. [Link]

Wu, C.C. and Y.H. Kuo, 1999: Typhoons affecting Taiwan: Current understanding and future challenges. Bull. Amer. Meteorol. Soc., 80, 67-80, doi: 10.1175/15200477(1999)080<0067:TATCUA>2.0.CO;2. [Link]

Wu, C.C., T. H. Yen, Y.H. Kuo, and W. Wang, 2002: Rainfall simulation associated with Typhoon Herb (1996) near Taiwan. Part I: The topographic effect. Weather Forecast., 17, 1001-1015, doi: 10.1175/1520-0434(2003)017<1001:RSAWTH>2.0.CO;2. [Link]

Wu, C. C., K. H. Chou, H. J. Cheng, and Y. Wang, 2003: Eyewall contraction, breakdown and reformation in a landfalling typhoon. Geophys. Res. Lett., 30, doi: 10.1029/2003GL017653. [Link]

Wu, C. C., K. H. Chou, P. H. Lin, S. D. Aberson, M. S. Peng, and T. Nakazawa, 2007: The impact of dropwindsonde data on typhoon track forecasts in DOTSTAR. Weather Forecast., 22, 1157-1176, doi: 10.1175/2007WAF2006062.1. [Link]

Wu, C. C., H. J. Cheng, Y. Wang, and K. H. Chou, 2009: A numerical investigation of the eyewall evolution in a landfalling typhoon. Mon. Weather Rev., 137, 21-40, doi: 10.1175/2008MWR2516.1. [Link]

Wu, C. C., Y. H. Huang, and G. Y. Lien, 2012: Concentric eyewall formation in Typhoon Sinlaku (2008). Part I: Assimilation of T-PARC data based on the Ensemble Kalman Filter (EnKF). Mon. Weather Rev., 140, 506527, doi: 10.1175/MWR-D-11-00057.1. [Link]

Xiao, Q., Y. H. Kuo, J. Sun, W. C. Lee, E. Lim, Y. R. Guo, and D. M. Barker, 2005: Assimilation of Doppler radar observations with a regional $3 \mathrm{DVAR}$ system: Impact of Doppler velocities on forecasts of a heavy rainfall case. J. Appl. Meteorol., 44, 768-788, doi: 10.1175/ JAM2248.1. [Link]

Xiao, Q., Y. H. Kuo, J. Sun, W. C. Lee, D. M. Barker, and E. Lim, 2007: An approach of radar reflectivity data assimilation and its assessment with the inland QPF of Typhoon Rusa (2002) at landfall. J. Appl. Meteorol. Climatol., 46, 14-22, doi: 10.1175/JAM2439.1. [Link]

$\mathrm{Xu}$, J. and Y. Wang, 2010a: Sensitivity of tropical cyclone inner-core size and intensity to the radial distribution of surface entropy flux. J. Atmos. Sci., 67, 1831-1852, doi: 10.1175/2010JAS3387.1. [Link]

$\mathrm{Xu}$, J. and Y. Wang, 2010b: Sensitivity of the simulated tropical cyclone inner-core size to the initial vortex size. Mon. Weather Rev., 138, 4135-4157, doi: 10.1175/2010MWR3335.1. [Link]

Yang, S. C., C. Keppenne, M. Rienecker, and E. Kalnay, 2009a: Application of coupled bred vectors to seasonal-to-interannual forecasting and ocean data assimilation. J. Climate, 22, 2850-2870, doi: 10.1175/2008JCLI2427.1. [Link]

Yang, S. C., M. Corazza, A. Carrassi, E. Kalnay, and T. Miyoshi, 2009b: Comparison of local ensemble transform Kalman filter, 3DVAR, and 4DVAR in a quasigeostrophic model. Mon. Weather Rev., 137, 693-709, doi: 10.1175/2008MWR2396.1. [Link]

Yang, Y. T., H. C. Kuo, E. A. Hendricks, and M. S. Peng, 2013: Structural and intensity changes of concentric eyewall typhoons in the Western North Pacific basin. Mon. Weather Rev., 141, 2632-2648, doi: 10.1175/ MWR-D-12-00251.1. [Link]

Yeh, T.C. and R. L. Elsberry, 1993a: Interaction of typhoons with the Taiwan orography. Part I: Upstream track deflections. Mon. Weather Rev., 121, 3193-3212, doi: 1 0.1175/1520-0493(1993)121<3193:IOTWTT>2.0.CO; 2. [Link]

Yeh, T. C. and R. L. Elsberry, 1993b: Interaction of typhoons with the Taiwan orography. Part II: Continuous and discontinuous tracks across the island. Mon. Weather Rev., 121, 3213-3233, doi: 10.1175/1520-049 3(1993)121<3213:IOTWTT>2.0.CO;2. [Link] 